Pediatr. Res. 17: 562-566 (1983)

\title{
Maturational Changes in the Regulatory Mechanisms of Hepatic Thyroxine 5'-Monodeiodination in Growing Rats
}

\author{
TAMOTU SATO, ${ }^{(27)}$ TAIZO KATO, SOHEI KAJIWARA, CHIAKI MIYAMORI, AND KYOKO KITA
}

Department of Pediatrics, School of Medicine, Kanazawa University, Takaramachi 13-1, Kanazawa City 920, Japan

\begin{abstract}
Summary
Changes in the regulatory mechanisms of hepatic thyroxine (T4) 5 -monodeiodination during maturational process were studied in rats aged 1,3 , and 6 wk and in adults. Despite low T4 $5^{\prime}$-deiodinase activity in the neonates, a similar degree of activation in older rats was obtained with graded doses of dithiothreitol. Lineweaver-Burk plot analysis showed that Vmax increased 1-3 wk of age, decreasing with age thereafter, whereas a high $\mathrm{Km}$ value in young rats $\left(7.0-7.8 \times 10^{-4} \mathrm{M}\right)$ fell to a level of $4.8 \times 10^{-4} \mathrm{M}$ by $6 \mathrm{wk}$ of age. T4 5'-deiodinase at 3 wk of age was relatively resistant to iodoacetamide, a SH blocking agent (11\% inhibition at $10^{-6} \mathrm{M}$ versus $47 \%$ in adult). Furthermore, it was markedly enhanced with $3 \mathrm{mM}$ EDTA (125\% versus $10-20 \%$ in older rats). Among various bivalent cations tested, $\mathrm{Cu}^{++}$and $\mathrm{Zn}^{++}$had a strong inhibitory effect on the reaction, whereas livers from 3-wk-old rats were less sensitive to $\mathrm{Zn}^{++}\left(7 \%\right.$ inhibition at $10^{-6} \mathrm{M}$ versus $\mathbf{4 0 \%}$ in adult). Responses to graded doses of reduced glutathione (GSH) or to its blocker, diamide, suggest that GSH exerts its promoting effect through preservation of protein SH radicals in reduced form. In contrast, NADPH stimulates the reaction directly, and a marked increase in the sensitivity to NADPH was observed 1-3 wk of age. Doseresponse relation to methylene blue (MB), inhibitor of NADPH, exhibited a biphasic effect on the reaction: stimulatory at smaller dose and inhibitory at larger dose. The critical dose of MB producing this reversal shifted to a lower level with advancing age, which appears to be due to the content of endogenous NADPH as well as to the reactivity of the enzyme to it. These results indicate that (1) protein SH radicals appear to change from a relatively inactive to an active state with age, in which an interaction with $\mathrm{Zn}^{++}$might be involved; (2) GSH is probably associated with the conversion of SH groups; (3) NADPH enhances directly the enzyme activity, playing a pivotal role in the regulation of the reaction; and (4) maturation of $\mathrm{T} 45^{\prime}$-deiodination includes changes in the protein SH groups and GSH-NADPH generating system.
\end{abstract}

Abbreviations

DTT, dithiothreitol

GSH, reduced glutathione

MB, methylene blue

PTU, propylthiouracil

SH, sulfhydryl

T3, 3,5,3'-triiodothyronine

T4, thyroxine

rT3, 3,3', $5^{\prime}$-triiodothyronine

It has been well established that T4 is deiodinated at the outer or inner phenolic ring position by $5^{\prime}$ - and 5-deiodinase in peripheral tissues, yielding T3 and rT3 respectively $(4,6,22)$. Both enzymes contain essential SH groups, and mercapto compounds such as DTT, 2-mercaptoethanol, and GSH enhance the deiodination. In contrast $\mathrm{SH}$ blocking agents such as thiouracil, $\mathrm{N}$ - ethylmaleinimide, iodoactamide and $p$-chloromercuribenzoate inhibit the reaction $(5,10,13,14,22-24)$. NADPH is also an important cofactor of T4 $5^{\prime}$-deiodinase and changes in the enzyme activity are closely associated with the hexose-monophosphate pathway $(2,10,18,19)$. In the fetal and neonatal period, hepatic T4 5'-monodeiodination is extremely low, which rises promptly after birth $(3,5,9-11,21,25)$. The reduced activity in this period is not due to deficiency of the enzyme protein per se, but to that of cofactors $(5,10,19)$. Recent observation by us suggests that GSH-NADPH cycle plays a regulatory role in the developmental maturation of T4 deiodinating system (19). Little is known, however, on details of the mechanism. In the present study, an attempt was made to elucidate the regulatory mechanism of hepatic T4 $5^{\prime}$ deiodinating system during maturational process by modulating the reaction with various doses of (1) SH activating agents: DTT, GSH, and cofactor, NADPH; (2) SH blocking agents: iodoacetamide, propylthiouracil (PTU), and diamide; and (3) EDTA and bivalent cations.

\section{MATERIALS AND METHODS}

Liver specimens were obtained from Wistar rats aged 1, 3, and $6 \mathrm{wk}$ and adult in females. The time of examination was selected on the basis of our previous observation (19) that T4 5'-deiodinase activity was low in the neonates, rising gradually with age up to 6 wk of age and decreasing again to adult level thereafter. At 3 wk of age, however, it was most prominently activated by the supplementation of NADPH and GSH; therefore, samples obtained at these four ages were used for the representative of maturational process. Liver was homogenized in 5 volumes of ice cold $0.1 \mathrm{M}$ phosphate buffer (pH 7.0) containing 5 mM EDTA with Teflon homogenizer. For studying the effects of EDTA or bivalent cations, EDTA was removed from the buffer. After centrifugation at $2500 \mathrm{rpm}$ for $10 \mathrm{~min}$ at $4^{\circ} \mathrm{C}$, the supernatant was used immediately for the determination of T $45^{\prime}$-deiodinase activity. When required, it was stored in refrigerator at $-20^{\circ} \mathrm{C}$ for several wk.

T4 5'-deiodinase activity was measured by the method of Chopra (4). One-half $\mathrm{ml}$ of assay mixture contained $200 \mu \mathrm{l}$ of $20 \%$ liver homogenate, $50 \mu \mathrm{l}$ of $\mathrm{T} 4(10 \mu \mathrm{g} / \mathrm{ml}$ in the buffer) and 250 $\mu l$ of phosphate-EDTA buffer. When an activator or an inhibitor was added, $50 \mu \mathrm{l}$ of the solution at various concentrations was substituted for the buffer. The mixture was usually incubated at $37^{\circ} \mathrm{C}$ for $60 \mathrm{~min}$. The reaction was stopped by the addition of 1.0 $\mathrm{ml}$ of ethanol. Generated T3 was extracted into ethanol (extraction rate; $85 \pm 5 \%$ ). After centrifugation, $25-100 \mu$ l of the supernatant was used for T3 double-antibody radioimmunoassay with commercially available kit (Eiken T3 RIA kit). Endogenous T3 concentration together with $\mathrm{T} 4$ cross reactivity in radioimmunoassay system was also measured in each sample and substracted from estimated T3 value. Protein concentration of the homogenates was determined by the method of Lowry et al. (15), using bovine serum albumin as the standard. Generated T3 was expressed as ng. $\mathrm{h}^{-1} \cdot \mathrm{mg}^{-1}$ protein or as a $\%$ activity of control samples without 
containing an activator nor an inhibitor. All assays were performed in duplicate.

As the activating agent, $0.125-5 \mathrm{mM}$ DTT and GSH, and $0.06-$ 1.0 NADPH were chosen. As for the inhibitors, $10^{-8}$ to $10^{-6} \mathrm{M}$ iodoacetamide (irreversible SH blocker) (14), $10^{-8}$ to $10^{-6} \mathrm{M}$ PTU (reversible inhibitor of $\mathrm{SH}$ radicals) (14), $0.125-5 \mathrm{mM}$ diamide (GSH inhibitor) (12), and 0.125-5 mM methylene blue (antagonist for NADPH) (1) were used. All these chemicals including L-T4 were purchased from Sigma Chemical Co. In the study of the effects of bivalent cations on the reaction, $10^{-6}$ to $10^{-3} \mathrm{M} \mathrm{CaCl}_{2}$, $\mathrm{MgCl}_{2}, \mathrm{MnCl}_{2}, \mathrm{FeCl}_{2}, \mathrm{ZnCl}_{2}$, and $\mathrm{CuSO}_{4}$ solutions were tested. Because of a limited amount of homogenate from $1 \mathrm{wk}$ of age, all of these studies could not be thoroughly made in the neonates. In dose-response relation to DTT, apparent $\mathrm{Vmax}$ and $\mathrm{Km}$ values were obtained by Lineweaver-Burk plot analysis, the regression lines of which were calculated from the least square method.

\section{RESULTS}

(1) Dose-response relation to DTT (Fig. 1). Basal T4 5'-deiodinase activity at $1 \mathrm{wk}$ of age is lower than those at $3 \mathrm{wk}$ and $6 \mathrm{wk}$ of age (1.2 versus 2.6 and $3.7 \mathrm{ng} \cdot \mathrm{h}^{-1} \cdot \mathrm{mg}^{-1}$ protein respectively); however, a similar degree of activation was obtained by the addition of $0.125-5 \mathrm{mM}$ DTT. Lineweaver-Burk plot analysis revealed that apparent Vmax increased from 16.6 to $20.2 \mathrm{ng} \cdot \mathrm{h}^{-1}$. $\mathrm{mg}^{-1}$ protein between $1-3 \mathrm{wk}$ of age, but decreased gradually to adult level thereafter $\left(12.4 \mathrm{ng} \cdot \mathrm{h}^{-1} \cdot \mathrm{mg}^{-1}\right.$ protein $) . \mathrm{Km}$ value was also high at $1-3$ wk of age ( 7.0 and $7.8 \times 10^{-4} \mathrm{M}$ respectively), but fell to $4.8 \times 10^{-4} \mathrm{M}$ by $6 \mathrm{wk}$ of age. These data suggest that changes in the capacity as well as the affinity of $\mathrm{SH}$ radicals of the enzyme protein occur during maturation.

(2) Dose-response relationships to iodoacetamide and PTU (Fig. 2). Liver homogenate from 3 wk of age was relatively resistant to iodoacetamide inhibition, which bound irreversibly to protein $\mathrm{SH}$ groups. At $10^{-6} \mathrm{M}$ concentration, a \% activity for control sample (without supplementation) was $89 \%$ at 3 wk of age, $73 \%$ at 6 wk of age, and $53 \%$ in adult rats. In contrast, this age-related change was not observed in the dose-response relation to PTU, which reacted reversibly with $\mathrm{SH}$ radicals (14).

(3) Effects of EDTA and bivalent cations (Fig. 3 and 4). The addition of EDTA showed an enhancing effect on T4 5'-deiodination, in which a remarkable difference was noted in relation to age (125\% increase from control activity in $3 \mathrm{wk}$ of age versus 10 $20 \%$ in older rats at $3.2 \mathrm{mM}$ ). Accordingly, effects of bivalent
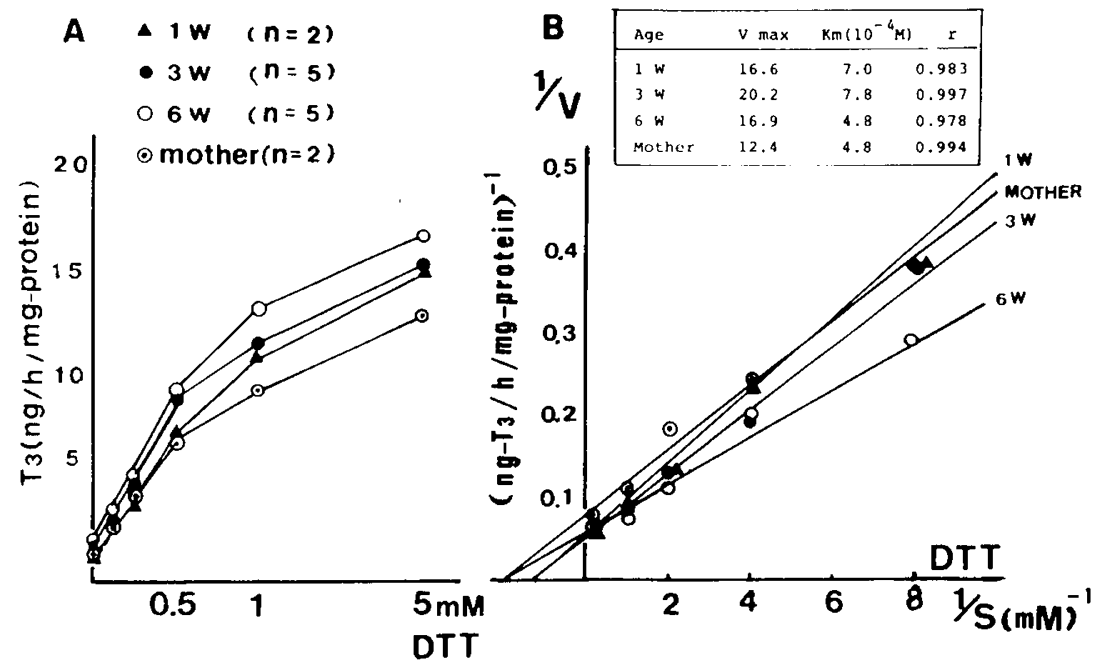

Fig. 1. Dose-response relation of $\mathrm{T} 3$ generation from $\mathrm{T} 4$ to graded doses of dithiothreitol $(A)$ in rat liver from $1 \mathrm{wk}(\boldsymbol{\Delta}), 3 \mathrm{wk}(\bullet), 6 \mathrm{wk}(O)$ of age and adult female rat $(\odot)$. Values are means of samples indicated in parenthesis. $(B)$ Lineweaver-Burk plot of each curve shown in $(A)$. Regression lines are obtained from the least square method and apparent Vmax and $\mathrm{Km}$ values and correlation coefficient of each age are listed in the table.
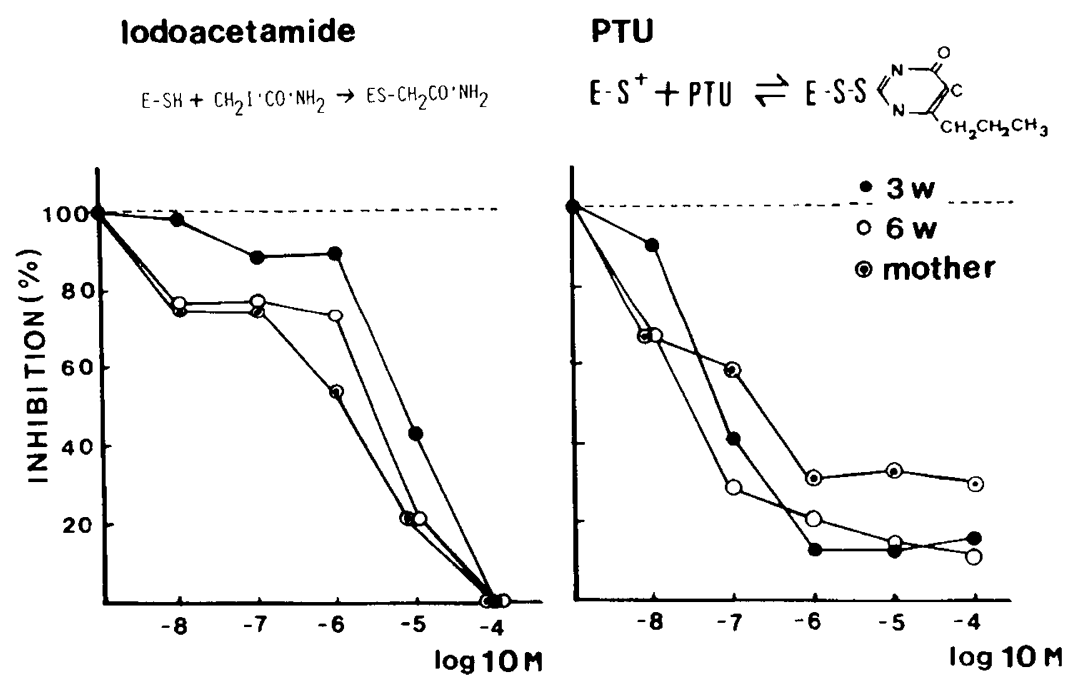

Fig. 2. Dose-dependent inhibition of $\mathrm{T} 4$ deiodinase activity by $10^{-8}$ to $10^{-4} \mathrm{M}$ iodoacetamide and propylthiouracil in liver from $3 \mathrm{wk}, 6 \mathrm{wk}$ of age, and adult. Values are expressed as per cent activity for control samples without inhibitor. Liver from $3 \mathrm{wk}$ of age is relatively resistant to iodoacetamide inhibition, but not propylthiouracil. See Figure 1 legend for explanation of symbols. 

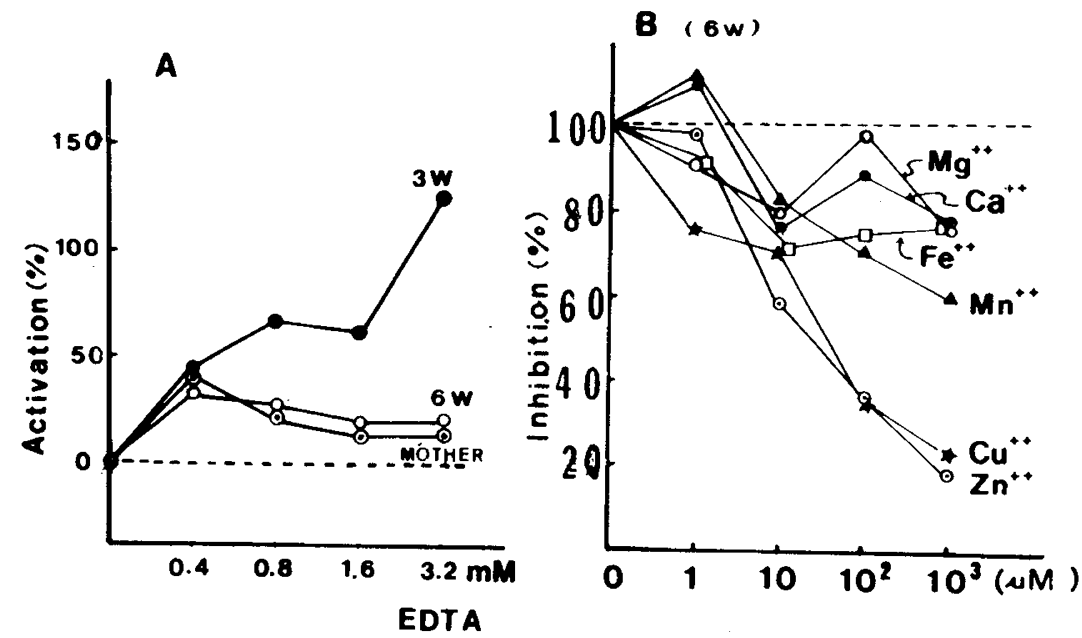

Fig. 3. (A) Comparison of EDTA-stimulated T4 5'-deiodinase activity in liver from $3 \mathrm{wk}, 6 \mathrm{wk}$ of age and adult rat. Specimen from $3 \mathrm{wk}$ of age is enhanced markedly by $3.2 \mathrm{mM}$ EDTA. $(B)$ Effect of $10^{-6}$ to $10^{-3} \mathrm{M}$ bivalent cations on $\mathrm{T} 45^{\prime}$-deiodination in 6 wk liver, which is expressed as $\%$ for control samples without supplementation. $\mathrm{Cu}^{++}$and $\mathrm{Zn}^{++}$show similar strong inhibition. See Figure 1 legend for explanation of symbols.
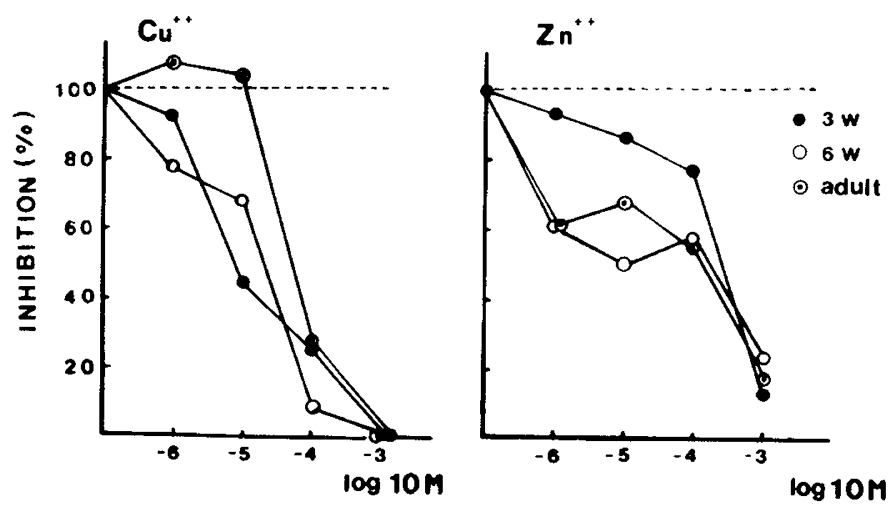

Fig. 4. Dose-dependent inhibition of $\mathrm{Cu}^{++}$and $\mathrm{Zn}^{++}$on $\mathrm{T} 45^{\prime}$-deiodination in liver from $3 \mathrm{wk}, 6 \mathrm{wk}$ of age, and adult rat. Liver from $3 \mathrm{wk}$ of age is less sensitive to $\mathrm{Zn}^{++}$inhibition at $10^{-6}$ to $10^{-4} \mathrm{M}$ concentrations. See Figure 1 legend for explanations of symbols.

cations ( $\mathrm{Ca}, \mathrm{Mg}, \mathrm{Mn}, \mathrm{Fe}, \mathrm{Zn}$ and $\mathrm{Cu}$ ) were examined. Of these, $\mathrm{Cu}^{++}$and $\mathrm{Zn}^{++}$showed strong inhibitory effect (Fig. 3B). Adult liver was less sensitive to $\mathrm{Cu}^{++}$inhibition, whereas liver from 3 wk of age was more resistant to $\mathrm{Zn}^{++}$inhibition (Fig. 4). Together with the result of dose-response relation to EDTA, action of $\mathrm{Zn}^{++}$ appears to be more physiologically significant than $\mathrm{Cu}^{++}$in $\mathrm{T} 45^{\prime}$ deiodinating system.

(4) Dose-response relationships to NADPH and/or GSH (Fig. 5). NADPH exhibited a marked activation of T4 $5^{\prime}$-deiodinase in all age samples, but the most prominent change was noted 1-3 wk of age. The maximally enhanced activity was 4-fold higher in $3 \mathrm{wk}$ than $1 \mathrm{wk}$ of age (Fig. 5A). Further supplementation of $1 \mathrm{mM}$ GSH did not alter the dose-response curve to NADPH (Fig. 5B). In contrast, a small but significant increase in the activity was obtained with graded doses of GSH (Fig. 5C). With the addition of $1 \mathrm{mM}$ NADPH to the system, however, this effect was eliminated in 6 wk of age and in adult rats, whereas a linear increase was still observed in 1 and 3 wk of age (Fig. 5D). These indicate - that NADPH has a promoting effect throughout the developmental process, whereas GSH is only rate limiting during the early stage of development.

(5) Dose-response relationship to diamide (Fig. 6). Diamide is known to be a blocker of GSH as well as protein SH group (12), to which adult liver was relatively resistant (38\% control activity in 3 wk versus $84 \%$ in adult at $0.125 \mathrm{mM}$ ). The addition of $5 \mathrm{mM}$ GSH to the system gave rise to only small increase in the activity

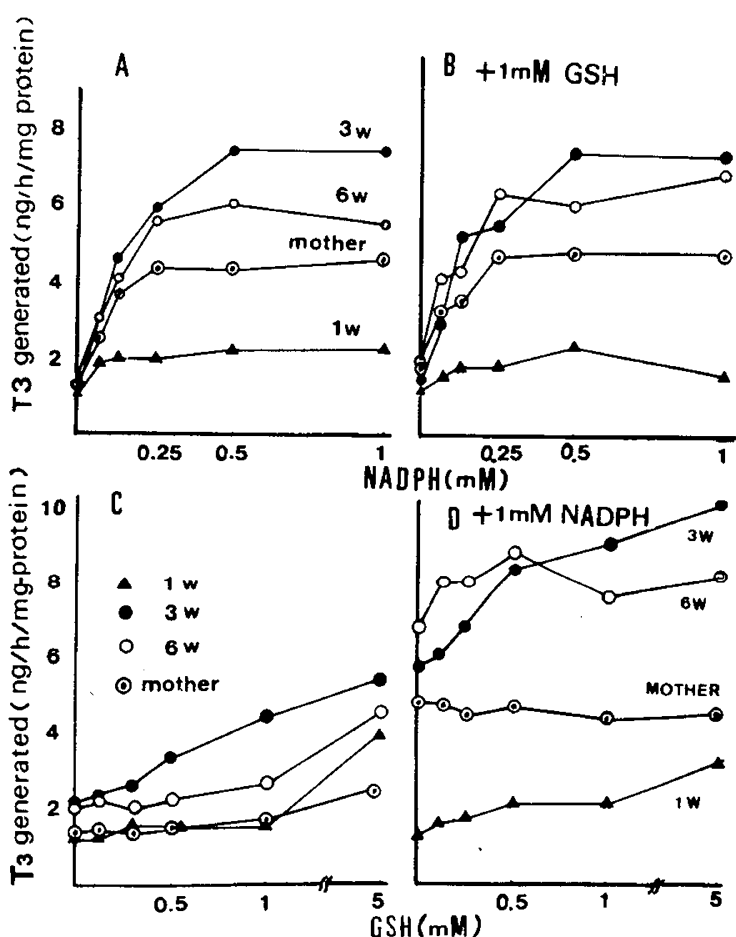

Fig. 5. Age-related changes in dose-response relation to NADPH $(A)$, $\mathrm{NADPH}+1 \mathrm{mM}$ reduced glutathione (GSH) $(B)$, GSH $(C)$ and GSH $+1 \mathrm{mM}$ NADPH $(D)$. A marked increase in activation by NADPH is observed between 1-3 wk of age, and the additive effect of GSH is not apparent. In contrast, stimulating effect of GSH is abolished by the addition of $1 \mathrm{mM}$ NADPH in $6 \mathrm{wk}$ of age and in adult rat, whereas it still remains in young rats. See Figure 1 legend for explanation of symbols.

at low concentration of diamide in young rats (Fig. 6B). The effect of GSH was clearly demonstrated in the stock livers, which were deficient in GSH content (Fig. 6C). These findings suggest that GSH is not involved directly in the deiodination, but rather participates indirectly, probably through the activation or protection of SH radicals of the enzyme protein (8).

(6) Dose-response relationship to methylene blue (Fig. 7). MB has a biphasic effect on T4 5'-deiodination: stimulating at lower dose and inhibiting at higher dose. The critical dose producing this phase reversal was decreased gradually with advancing age (Fig. 7A). In stock livers that were depleted of NADPH, the effect of 

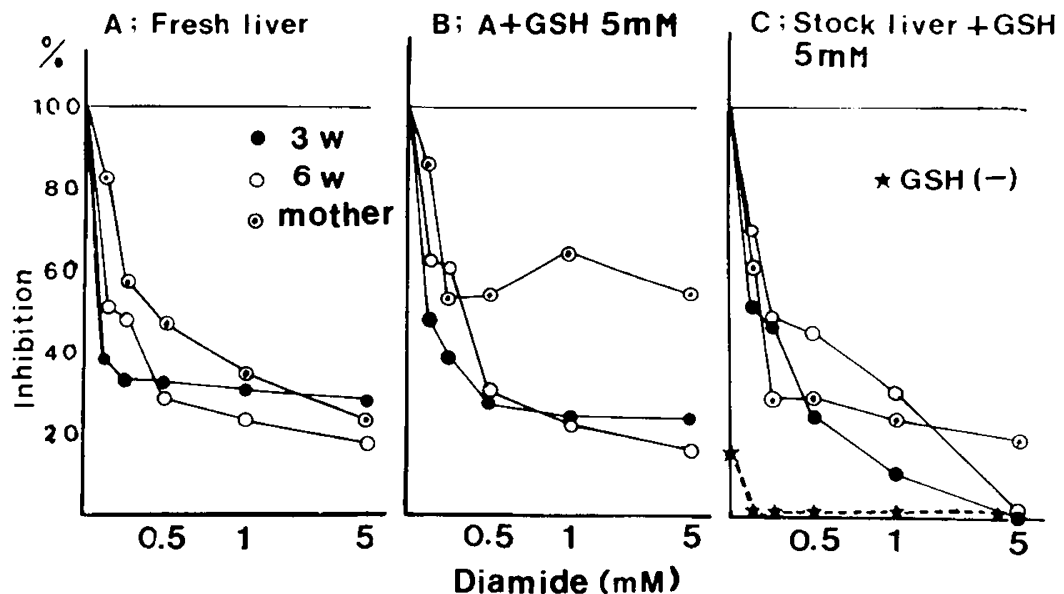

Fig. 6. Dose-response relation to T4 5'-deiodinase activity to diamide, which is expressed as a \% activity for control samples without supplementation. Adult liver is relatively resistant to inhibition by diamide $(A)$. The addition of $5 \mathrm{mM} \mathrm{GSH}$ slightly reduced the inhibition at lower doses of diamide in young rats $(B)$, whereas the definite activation is noted in stock liver $(C)$. Dotted line indicates basal T4 $5^{\prime}$-deiodinating activity of stock liver. See Figure 1 legend for explanation of symbols.

A; Fresh liver

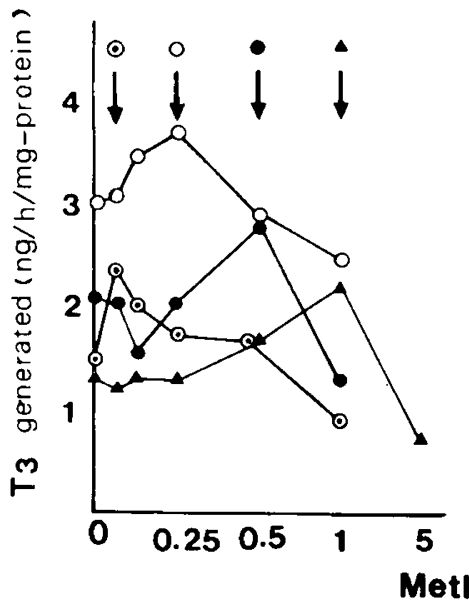

B; Stock liver

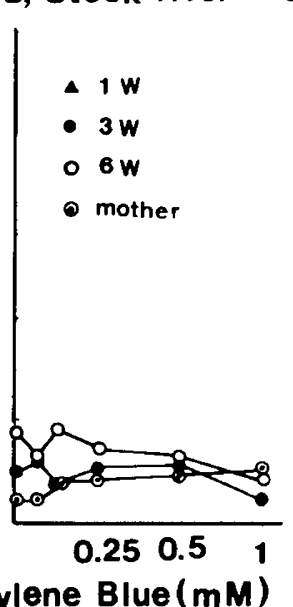

C; Stock liver

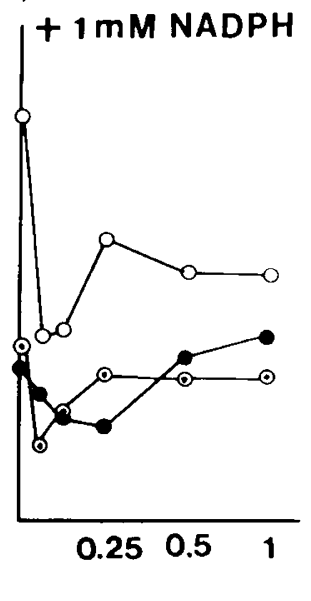

Fig. 7. Biphasic effect of methylene blue on T5 5 '-deiodination. The critical dose of methylene blue causing phase reversal is decreasing with age (indicated by arrows). The effect of methylene blue is not apparent in stock livers depleted of NADPH $(B)$, whereas the addition of $1 \mathrm{mM}$ NADPH restores their reactivity to methylene blue $(C)$. See Figure 1 legend for explanation of symbols.

MB was not apparent (Fig. 7B), but the supplementation of $1 \mathrm{mM}$ NADPH restored partially the reactivity (Fig. 7C); therefore, MB exerts its effect via NADP-NADPH cycle on the reaction (1), and the age-related shift in reverse point is presumably associated with change in the endogenous NADPH content during maturation.

\section{DISCUSSION}

On the mechanism of action of iodothyronine 5 -deiodinase, Visser (23) proposed a ping-pong mechanism. In the first step of the reaction, iodothyronine $\left(T-I_{n}\right)$ reacts with protein $\mathrm{SH}(\mathrm{E}-\mathrm{SH})$, forming a $\mathrm{T}-\mathrm{I}_{\mathrm{n}}$-enzyme complex, in which transiodination occurs, yielding an iodo-enzyme complex (E-SI) and T- $\mathrm{I}_{n-1}$. E-SI is subsequently reduced by coenzyme $(2 \mathrm{R}-\mathrm{SH})$, producing a reduced form of enzyme (E-SH), oxidized cofactor (R-SS-R), and hydroiodide. If this is the case, at least three regulatory factors are conceivable: the amount of enzyme, the state of protein $\mathrm{SH}$ radicals, and available cofactor(s).

In the fetal and neonatal period, T4 5-monodeiodination is by far the prominent pathway and abrupt shift to T4 $5^{\prime}$-monodeiodination occurs after birth $(3,9,10)$. In chick embryo, this maturational change in T4 metabolism coincides with initiation of air breathing (3); however, 5'-monodeiodination converting rT3 to $3,3^{\prime}$-diiodothyronine $\left(3,3^{\prime}-\mathrm{T} 2\right)$ is working actively in the early stage of embryos (3). Furthermore, the exogenous addition of DTT enhances $5^{\prime}$-deiodinase activity to an adult level $(3,5)$; therefore, an adequate amount of $5^{\prime}$-deiodinase as well as protein $\mathrm{SH}$ groups are present in the early stage of the developmental process, and low activity of the enzyme is ascribed to the deficiency of cofactor(s) (5). The results of the present study, however, suggest that the state of functional SH groups of the enzyme is also altered in the neonatal period. This is indicated from the observations that (1) kinetic parameters of T4 5'-deiodinase to DTT are altered: low Vmax and high $\mathrm{Km}$ value; (2) protein SH radicals are less sensitive to iodoacetamide inhibition; and (3) they are also resistant to $\mathrm{Zn}^{++}$ inhibition, whereas EDTA enhances markedly the enzyme activity. Accordingly, it is possible that $\mathrm{SH}$ groups in the enzyme are in a masked state, being in disulfide form or bound to $\mathrm{Zn}^{++}$. The different reactivity of the enzyme to iodoacetamide and PTU also supports the concept, because iodoacetamide reacts irreversibly to free $\mathrm{SH}$ groups (E-SH), whereas PTU inhibition results from an interaction with enzyme disulfide $\left(\mathrm{E}-\mathrm{S}^{+}\right)$, which can be reversed by thiols $(13,14)$.

There have been few reports on the effect of bivalent cations on T4 5'-deiodination. Chopra (4) found that high concentration of $\mathrm{CaCl}_{2}$ and mercury are inhibitory to the reaction, whereas EDTA 
had no appreciable effect. In our experiences, however; the activating effect of EDTA was repeatedly demonstrated in liver homogenates from young rats. This indicates that some bivalent cations act as a modulator of T4 5'-deiodination. Actually, $\mathrm{Cu}^{++}$ and $\mathrm{Zn}^{++}$were proved to be inhibitory at a concentration of $10^{-5}$ to $10^{-3} \mathrm{M}$. The hepatic content of zinc in the fetal and the neonatal rats was reported to be 2-3-fold greater than that of the adult and remained at this level for at least the first $2 \mathrm{wk}$ of postnatal life (16). It is conceivable that the high level of zinc in the neonatal liver may exert an inhibitory effect on T4 5'-deiodinase activity. Although this assumption has not been confirmed, our findings suggests a close association of zinc with $\mathrm{T} 45^{\prime}$-monodeiodination. It requires further purification of the enzyme to determine whether T4 $5^{\prime}$-deiodinase contains zinc as the essential functional element or not.

As for the cofactor of T4 5'-deiodination, GSH is regarded as essential to the reaction $(2,10)$. Recently, evidence against this concept have also been presented $(7,17)$. It is evident that GSH plays a significant role in the T4 deiodinating system, because (1) GSH enhances T3 generation dose-dependently in vitro; (2) stock liver homogenate restores the deiodinating activity with the addition of GSH; and (3) age-related changes in T3 production parallel to the endogenous content of GSH in liver (19). But the enhancing effect of GSH is too small to be an essential cofactor of the reaction, and the stimulating effect of GSH is diminished in the course of maturation. Probably GSH exerts its promoting effect through preservation of SH radicals in the reduced form. In contrast, NADPH exhibited a marked stimulating effect throughout the developmental period. NADPH is known to be a cofactor of GSH generating system, and it has been a matter of controversy whether NADPH acts directly on T4 deiodination or indirectly via GSH formation. Balsam and Ingbar (2) proposed that NADPH promoted T4 deiodination within cytosol, by increasing the concentration of GSH through the action of glutathione reductase, because NADPH did not show any effect on microsomal fraction. The results of the present study and of our previous observations $(18,19)$ conflict with those of Balsam and Ingbar. Dose-dependent activation of NADPH is always greater than that of GSH and the additive effect of GSH to NADPH is not apparent (Fig. 5B), whereas that of NADPH to GSH is prominent (Fig. 5D). The addition of GSH to graded doses of MB, the blocking agent of NADPH, did not alter the dose-dependent inhibition of MB (18). These suggest that NADPH seems to accelerate directly T4 5'deiodination and to be more rate-limiting as a cofactor of the reaction. The exact cause of discrepancy between our findings and that by Balsam and Ingbar is unknown, but recently it has been demonstrated that there are two different $5^{\prime}$-deiodinases: cytosolic and microsomal, each working under different kinetics (20). Although the enzyme preparation used in this study includes cytosolic and microsomal fractions, the results indicate that NADPH plays a pivotal role in the reduction of T4-enzyme complex, whereas GSH participates in the conversion of disulfide bound to reduced SH form. Maturational changes in T4 $5^{\prime}$-deiodination take place in both steps of the reaction as well as in T4 $5^{\prime}$ deiodinase per se.

\section{REFERENCES AND NOTES}

1. Ammon, H. P. T. and Verspohl, E. J.: Effect of methylene blue on pyridine nucleotides and insulin secretion of rat pancreatic islets. Diabetologia, 17:41 (1979).

2. Balsam, A. and Ingbar, S. H.: Observations on the factors that control the generation of triiodothyronine from thyroxine in rat liver and the nature of the effect induced by fasting. J. Clin. Invest., 63: 1145 (1979).
3. Borges, M., LaBourene, J., and Ingbar, S. H.: Changes in hapatic iodothyronine metabolism during ontogeny of the chick embryo. Endocrinology, 107: 1751 (1980).

4. Chopra, I. J.: A study of extrathyroidal conversion of thyroxine (T4) to 3,3',5triiodothyronine (T3) in vitro. Endocrinology, 101: 453 (1977).

5. Chopra, I. J.: Sulfhydryl groups and the monodeiodination of thyroxine to triiodothyronine. Science, 199: 904 (1978).

6. Chopra, I. J.: Characteristics of outer ring (5'- or $\left.3^{\prime}-\right)$ monodeiodination of $3^{\prime}, 5^{\prime}$ and 3,3'-diiodothyronine: Evidence suggesting one outer ring monodeiodinase for various iodothyronines. Endocrinology, 108: 464 (1981).

7. Gavin, L. A., MacMahorn, L. A., and Moeller, M.: Dietary modification of thyroxine deiodination in rat liver is not mediated by hepatic sulfhydryls. $\mathrm{J}$. Clin. Invest., 65: 943 (1980).

8. Granberg, J. P. and Ballard, P. L.: The role of sulfhydryl groups in the binding of glucocorticoids by cytoplasmic receptors of lung and other mammalian tissues. Endocrinology, 100: 1160 (1977).

9. Harris, A. R. C., Fang, S. L., Prosky, J., Braverman, L. E., and Vagenakis, A. G.: Decreased outer ring monodeiodination of thyroxine and reverse triiodothyronine in the fetal and neonatal rat. Endocrinology, 103: 2216 (1978).

10. Harris, A. R. C., Fang, S. L., Hinerfeld, L., Braverman, L. E. and Vagenakis, A. G.: The role of sulfhydryl groups on the impaired hepatic 3,3',5-triiodothyronine generation from thyroxine in the hypothyroid, starved, fetal and neonatal rodent. J. Clin. Invest., 63: 516 (1979).

11. Köhrle, J., Ködding, R., Wong, C. C., and Hesch, R. D.: Age-dependent changes of thyroxine-deiodination in rat liver. Acta Endocrinol. (Kbh) Suppl., 225: 20 (1979).

12. Kosower, N. S., Kosower, E. M., and Wertheim, B.: Diamide, a new reagent for the intracellular oxidation of glutathione to the disulfide. Biochem. Biophys. Res. Comm., 37: 593 (1969).

13. Leonard, J. L. and Rosenberg, I. N.: Thyroxine $5^{\prime}$-deiodinase activity of rat kidney-Observations on activation by thiols and inhibition by propylthiouracil. Endocrinology, 103: 2137 (1978).

14. Leonard, J. L. and Rosenberg, I. N.: Characterization of essential enzyme sulfhydryl groups of thyroxine 5'-deiodinase from rat kidney. Endocrinology, 106: 444 (1980)

15. Lowry, O. H., Rosebrough, N. J., Farr, A. L., and Randall, R. J.: Protein measurement with Folin phenol reagent. J. Biol. Chem., 193: 256 (1951).

16. Mason, R., Bakka, A., Samarawickrama, G. P., and Webb, M.: Metabolism of zinc and copper in the neonate; accumulation and function of $\mathrm{Zn}, \mathrm{Cu}$-metallothionein in the liver of the new born rats. Brit. J. Nutr., 45: 375 (1980).

17. Sato, K. and Robbins, J.: Glutathione deficiency induced by cystine and/or methionine deprivation does not affect thyroid hormone deiodination in cultured rat hepatocytes and monkey hepatocarcinoma cells. Endocrinology. 109: 844 (1981).

18. Sato, T., Maruyama, S., and Nomura, K.: On the role of NADPH and glutathione in the catalytic mechanism of hepatic thyroxine 5'-deiodination. Endocrinol. Japon., 28: 451 (1981).

19. Sato, T., Maruyama, S., Saida, K. and Takata, I.: Correlated maturation of thyroxine $5^{\prime}$-monodeiodination with hexose-monophosphate shunt in young rats. Pediatr. Res., 16: 377 (1982).

20. Smallridge, R. C., Burman, K. D., Ward, K. E., Wartofsky, L., Dimond, R. C., Wright, F. D., and Latham, K. R.: 3',5'-diiodothyronine to $3^{\prime}$-monoiodothyronine conversion in the fed and fasted rat: enzyme characteristics and evidence for two distinct 5'-deiodinase. Endocrinology, 108: 2236 (1981).

21. Suzuki, Y., Kita, K., Uchigata, Y., Takata, I., and Sato, T.: Maturation of renal and hepatic monodeiodination of thyroxine to triiodothyronine and post-natal changes of serum thyroid hormones in young rats. Acta Endocrinol. (Kbh), 99: 540 (1982).

22. Visser, T. J., Van der Does-Tobé, I., Docter, R. and Hennemann, G.: Subcellular localization of a rat liver enzyme converting thyroxine into triiodothyronine and possible involvement of essential thiol groups. Biochem. J., 157: 479 (1976).

23. Visser, T. J.: Mechanism of action of iodothyronine 5'-deiodinase. Biochim. Biophys. Acta, 569: 302 (1979).

24. Visser, T. J. and Overmeeren-Kaptein, E. V.: Substrate requirement for inactivation of iodothyronine-5'-deiodinase activity by thiouracil. Biochim. Biophys. Acta, 658: 202 (1981).

25. Wu, S. Y., Klein, A. H., Chopra, I. J., and Fisher, D. A.: Alteration in tissue thyroxine-5'-monodeiodinating activity in perinatal period. Endocrinology, 103: 235 (1978).

26. This work is supported in part by the Grant from Growth Science Association in Japan.

27. Requests for reprints should be addressed to Tamotu Sato, M.D., Department of pediatrics, School of Medicine, Kanazawa University, Takaramachi 13-1, Kanazawa City 920, Japan.

28. Received for publication May 7, 1982.

29. Accepted for publication October 18, 1982 